\title{
Study on Merits and Demerits of Two Transport Systems: Battery Operated Easy Bike with CNG Operated Auto Rickshaw at Sylhet City in Bangladesh
}

\author{
Mohammad Iqbal ${ }^{1}$, Salma Akhter ${ }^{2}$, Shibbir Ahmad ${ }^{3}$ \\ ${ }^{I}$ (Department of Industrial and Production Engineering, Shah jalal University of Science and Technology, \\ Bangladesh) \\ ${ }^{2}$ (Department of Chemical Engineering and Polymer Science, Shah jalal University of Science and Technology, \\ Bangladesh) \\ 3(Department of Industrial Engineering, East West Industrial Park Limited, Bangladesh)
}

\begin{abstract}
Auto rickshaws are tiny, three-wheeled vehicles which are used extensively in many Asian countries for transport of people and goods. The vehicles are small and narrow allowing for easy maneuverability in congested Asian metropolises. In Bangladesh, auto rickshaws are commonly used as taxis. This is due to the use of an engine, typically a 2 or 4 stroke, with almost no pollution control. Usually fuels are used in auto rickshaws. But a few years ago some auto rickshaws have been imported from china which is run by battery. The numbers of battery powered auto rickshaws are increasing day by day. This research paper includes comparison study of battery operated easy bike with CNG (Compressed Natural Gas) operated auto rickshaw in terms of cost (operating cost, manufacturing cost, maintenance cost), user friendly and environmental issue.
\end{abstract}

Keywords - Cost, Maintenance, Safety and Transport, urban, CNG.

\section{INTRODUCTION}

Most of the cities in developing countries are highly polluted. The main reasons are air and noise pollution caused by transport vehicles, especially petrol-powered two and three wheelers. For example, in India there are close to 18 million petrol powered two wheelers and about 1.5 million petrol and diesel powered three wheelers. Their population is growing at a healthy rate of about $15 \%$ per annum [1].

Alternative energy solutions received a great deal of attention in the last decade due to the need of sustainable and environmental friendly energy sources. The main pollutant source in urban areas is the emission of vehicles with ICE (Internal Combustion Engine). Increased concerns over global and local pollution, depletion of fossil fuels, and higher gas prices have motivated ambitious plans for new vehicle types with alternative energy sources. Hybrid electrical vehicles that combine the advantages of two power sources, ICE and electrical motors, have been the focus of attention recently. A two or four stroke gasoline engine usually powers these vehicles. In recent years, alternatives such as CNG and LPG (Liquefied Petroleum Gas) models have been introduced to deal with the pollution problem. While these vehicles reduce the amount of particulate matter and other harmful pollutants they do not eliminate them and cities where rickshaws are numerous will continue to have poor air quality. The capital city of Bangladesh is one of the most polluted cities in the world although the majority of the public transport is currently based on the CNG technology.

\section{HEADING S BACKGROUND OF THE STUDY}

The Auto rickshaws are one of the most popular means of transportation in Bangladesh and other countries. Although they have many benefits, including small size, lightweight, and low cost. Auto rickshaws are very noisy, inefficient, expel a high degree of pollutants and keep Bangladesh dependent upon foreign oil consumption. Auto rickshaws are available in diesel, compressed natural gas (CNG), and liquefied petroleum gas (LPG) models. The operating costs of these are lower than rickshaws running on gasoline; however, the higher initial costs keep the fare of these rickshaws the same as its gasoline counterpart. The use of alternative energy in transportation is being explored as a solution to the problems experienced with the auto rickshaw. 


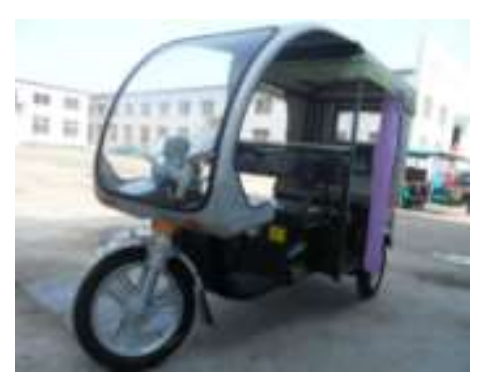

Fig. 1: Electrical powered Auto rickshaw.

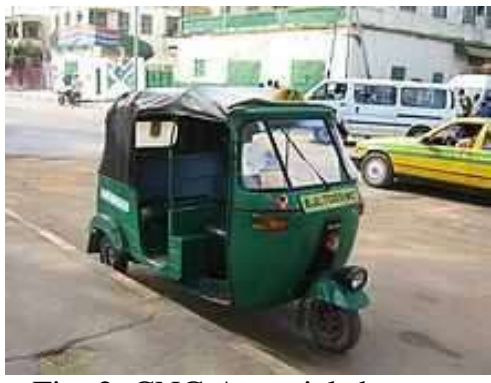

Fig. 2: CNG Auto rickshaw.

An electric cycle rickshaw can provide a non-polluting and a very silent transport system for urban and rural areas and busy cities. The low rolling resistance and light weight make this vehicle very energy efficient and cost effective. Work done at major research Institutions has shown that improved cycle rickshaws powered by electric motors and batteries have a potential to provide an attractive alternative to petrol and diesel powered three wheelers. Besides they can also provide large scale employment and extra income to the rickshaw operator, without affecting his or her health [2].

\subsection{Objective}

Main objective of the research work:

To find the differences between the two public transport namely Battery Powered Easy Bike and CNG powered Auto Rickshaw in terms of cost (operating cost, manufacturing cost, maintenance cost), user friendly and environmental issue.

\subsection{History of Autorickshaws}

\section{LITERATURE REVIEW}

Auto rickshaws (locally called "baby taxis" and more recently "CNGs" due to their fuel source) are one of the most popular modes of transport in Bangladesh mainly due to their size and speed. They are best suited to narrow, crowded streets, and are thus the principal means of covering longer distances within urban areas [3]. Earlier, auto rickshaws were colored black with a yellow canvas topping and ran on gasoline without any meter system. However, due to the vast supplies of natural gas in Bangladesh, the government has since encouraged the development of four-stroke compressed natural gas (CNG)-powered engines rather than the older two stroke engine petrol-running models. Two-stroke engines had been identified as one of the leading sources of air pollution in Dhaka. Thus, since January 2003, traditional auto rickshaws were banned from the capital; only the new CNG-powered models were permitted to operate within the city limits. The newly manufactured CNG auto rickshaws are more fuel-efficient and have a lower center of gravity, making them safer than older models. All CNGs are painted green to signify that the vehicles are eco-friendly and that each one has a meter built in as standard.

At the end of the 1980s, a local company Atlas designed and built a new version of the auto rickshaw, called mishuk, a name derived from a children's mascot of a local deer. Unlike baby taxis, mishuks have spoke wheels and a green body, and have no meter system. Mishuks have more space than baby taxis or CNGs, which makes it more popular with women. They are commonly found in Dhaka and elsewhere in the country due to its four-stroke engine, which is not listed as a significant source of air pollution [3].

\section{a) Bangladesh}

Auto rickshaws (locally called "baby taxis" and more recently "CNGs" due to their fuel source) are one of the most popular modes of transport in Bangladesh mainly due to their size and speed. They are best suited to narrow, crowded streets, and are thus the principal means of covering longer distances within urban areas.Earlier, auto rickshaws were colored black with a yellow canvas topping and ran on gasoline without any meter system. However, due to the vast supplies of natural gas in Bangladesh, the government has since encouraged the development of four-stroke compressed natural gas (CNG)-powered engines rather than the older two stroke engine petrol-running models. Two-stroke engines had been identified as one of the leading sources of air pollution in Dhaka. Thus, since January 2003, traditional auto rickshaws were banned from the capital; only the new CNG-powered models were permitted to operate within the city limits. The newly manufactured CNG auto rickshaws are more fuel-efficient and have a lower center of gravity, making them safer than older models. All CNGs are painted green to signify that the vehicles are eco-friendly and that each one has a meter built in as standard. 


\section{b) India}

Auto rickshaws (often called just auto) are common all over India, and provide cheap and efficient transportation. New auto rickshaws ones run on CNG and are environment friendly. Typical mileage for an Indian-made auto rickshaw is around 35 kilometers per liter of petrol (about $2.9 \mathrm{~L}$ per $100 \mathrm{~km}$, or 82 miles per gallon [United States (wet measure), 100 miles per gallon Imperial.

c)

Philippines

Auto rickshaws are an especially popular form of public transportation in the Philippines, where they are referred to as "tricycles". In the Philippines, the design and configuration of tricycles varies widely from place to place, but tends towards rough standardization within each municipality.

d)

Sri Lanka

Auto rickshaws, commonly known as 'three-wheelers', can be found on all roads in Sri Lanka from the curvy roads through the hill country to the congested roads of Colombo transporting locals, foreigners, or freight about. Sri Lankan tuk-tuks are of the style of the light Phnom Penh type.

e)

\section{Thailand}

The auto rickshaw, called tuk-tuk (Thai: ตุ๊กต๊ก) in Thailand, is a widely used form of urban transport in $\underline{B a n g k o k}$ and other Thai cities, as well as other major Southeast Asian and South Asian cities. It is particularly popular where traffic congestion is a major problem, such as in Bangkok and Nakhon Ratchasima.

\subsection{Previous Work}

On auto rickshaw various studies have been performed over last couple of decades. Many papers and articles have been published on Electrical and CNG Auto rickshaws.

A thesis paper titled "Heavy duty vehicle emission testing" by Ronald Jarret, under Dr. Nigel Clark, Professor of Mechanical and Aerospace department, in West Virginia University was published in December 2000. They wanted to test the emission level from heavy duty vehicles and their environmental impacts [4].

An articles titled "Electronic differential with sliding mode controller for a direct wheel drive electric vehicle” by Gair, S., A. Cruden, J. McDonald, and B. Hredzak at International Conference on Mechatronics was published in 2004. The article discusses single drive systems and multi-drive systems. With multi-drive systems the motor controllers must additionally be configured to provide an electronic differential effect [5].

An Entrepreneurial projects program at Illinois Institute of Technology under title "Solar/battery hybrid three-wheel auto rickshaw for India" was done by Mulhall, P., M. Naviwala, S. M. Lukic, J. Baraband, and A. Emadi, at Vehicle Power and Propulsion Conference, University of Texas, Arlington, USA was published in 2007. This project includes research on the conventional auto rickshaw, future conceptual infrastructure designs for electric rickshaws, and the recent design research and simulations of the next auto rickshaw [5].

A journal paper under the title "A Study of Fuel Cell Hybrid Auto Rickshaws Using Realistic Urban Drive Cycles" was published in Jordan Journal of Mechanical and Industrial Engineering(JJMIE) By Mohammed Abu Mallouh, Bradley Denman, Brian Surgenor, Brant Peppley in January 2010. The paper tried to discuss the comparison between ICE and hybrid fuel cell rickshaw configuration was done using a realistic drive cycle [6]. A research paper based on "Development of a Micro-Hybrid System for a Three Wheeled Motor Taxi” By T. Hofman, S.G. van der Tas, W. Ooms, E.W.P. van Meijl, and B.M. Laugeman at Stavanger, Norway, was published in 2009. The goal of the research in this paper was to develop a compact, robust and affordable hybrid system in order to significantly reduce the fuel consumption and emissions of auto-rickshaws $[7]$.

\section{DATa COLLECTION AND ANALYSIS}

Research Methodologies: Methodology is generally a guideline for solving a problem, with specific components such as phases, tasks, methods, techniques and tools. In this data collection, both qualitative (Interviews) and quantitative (Questionnaires) research methods have been used.

This section deals with the findings from the data collected, tabulated form and graphical representation of these data and the analysis of those data. From those data's, analysis were done to compare the two public transport namely Battery operated Easy Bike and CNG operated Auto Rickshaw. Concentration has been given on to cost, manufacturing, resource, maintenance, structure, safety and other related issue.

\subsection{Data Collection}

Data were collected on the following factors for both CNG operated Auto Rickshaw and Battery operated Easy bike are as follows: 
- Made in (Manufacturer)

- Cost

- Number of vehicles available

- Monthly income of the owner

- Maintenance cost

- Monthly income of the driver

- Structure and total system of the vehicle

- Safety aspect of vehicle in terms of

- Made in (Manufacturer)

- Drivers safety

- Training of driver

- Night driving

- Environment friendly

- Ease of use

- Safety

- Comfort ability

\subsubsection{Made in (manufacturer)}

It is found from questionnaire that $\mathrm{CNG}$ operated auto rickshaw is imported from two countries namely India and China. Battery powered easy bike is mainly imported from china.

\subsubsection{Cost}

The cost of parts imported from India of CNG operated auto rickshaw is more costly than the parts imported from china. The cost of a CNG operated auto rickshaw imported from India is around 3-4 lacs taka, and imported from china is 3-3.50 lacs taka. But the businessmen of Bangladesh prefer to import CNG operated auto rickshaw from India due to government policy. Battery powered easy bike is imported from china. The cost of each vehicle is between 1.2- 1.3 lacs taka.

\subsubsection{Number of Vehicles Available}

There are around 30000-40000 CNG operated auto rickshaws and around 20000 battery operated easy bikes in Sylhet city.

\subsubsection{Daily Income}

The daily income of owners and drivers of CNG operated auto rickshaw and battery operated easy bike are shown in table below:

Table 1: Daily income of Drivers and owners.

\begin{tabular}{|l|l|l|}
\hline Daily income & $\begin{array}{l}\text { CNG operated } \\
\text { Auto Rickshaw }\end{array}$ & $\begin{array}{l}\text { Battery } \\
\text { operated Easy } \\
\text { Bike }\end{array}$ \\
\hline Driver & $400-500 \mathrm{Tk}$. & $200-300 \mathrm{Tk}$. \\
\hline Owner & $500 \mathrm{Tk}$. & $350 \mathrm{Tk}$. \\
\hline
\end{tabular}

From table 1 it is seen that the daily income of CNG operated auto rickshaw driver is 400-500 taka and the owner income is 500 taka. Similarly daily income of battery operated easy bike driver is 200-300 taka and the owner income is 350 taka.

The monthly income of CNG operated auto rickshaw driver is 12000-15000 taka and the owner is 15000 taka. Similarly monthly income of battery operated easy bike driver is 6000-9000 taka and the owner income is 10500 taka.

\subsubsection{Maintenance Cost}

According to the data collected the maintenance cost of CNG operated auto rickshaw is Tk. 3000-4000 per month and for battery operated easy bike is Tk. 2000-3000. 
Table 2: Maintenance work of CNG operated Auto Rickshaw and Battery operated Easy Bike.

\begin{tabular}{|l|l|l|l|l|}
\hline $\begin{array}{l}\text { Maintenance } \\
\text { Work }\end{array}$ & $\begin{array}{l}\text { CNG } \\
\text { operated } \\
\text { Auto } \\
\text { Rickshaw }\end{array}$ & Reason & $\begin{array}{l}\text { Battery operated } \\
\text { Easy Bike }\end{array}$ & Reason \\
\hline Brake repair & Less & Strong braking system & More & Weak braking system \\
\hline Light repair & Less & $\begin{array}{l}\text { Due to strong light } \\
\text { position }\end{array}$ & More & $\begin{array}{l}\text { Due to weak light } \\
\text { position }\end{array}$ \\
\hline $\begin{array}{l}\text { Electrical } \\
\text { Problem }\end{array}$ & Less & Use CNG as fuel & More & $\begin{array}{l}\text { Use electrical energy } \\
\text { as fuel }\end{array}$ \\
\hline $\begin{array}{l}\text { Mechanical } \\
\text { Problem } \\
\bullet \quad \text { Controller } \\
-\quad \text { Steering } \\
\text { Motor }\end{array}$ & Less & $\begin{array}{l}\text { Strong relationship in this } \\
\text { mechanical part }\end{array}$ & More & Weak relationship \\
\hline
\end{tabular}

From table 2 it is seen that CNG operated Auto Rickshaw has stronger braking system than Battery operated Easy Bike. Lighting position for CNG Auto Rickshaw is better than Easy Bike. CNG operated Auto Rickshaw has less electrical problem than Easy Bike. Controlling power is more in CNG Auto Rickshaw than Easy Bike.

Table 3: Comparison of Battery Powered Easy Bike and CNG Powered Auto Rickshaw in terms of Cost.

\begin{tabular}{|c|c|c|}
\hline Factors & CNG operated Auto Rickshaw & Battery operated Easy bike \\
\hline Maintenance cost (monthly) & $3000-4000 \mathrm{Tk}$. & $2000-3000 \mathrm{Tk}$. \\
\hline Daily income (Driver) & $1000-1200 \mathrm{Tk}$. & $700-800 \mathrm{Tk}$. \\
\hline Daily expenses(Driver) & $200-250 \mathrm{Tk}$. & $150-200 \mathrm{Tk}$. \\
\hline Owner daily income & $500 \mathrm{Tk}$. & $350 \mathrm{Tk}$. \\
\hline $\begin{array}{c}\text { Manufacturing Cost( With } \\
\text { assembling) }\end{array}$ & $300000-400000 \mathrm{Tk}$. & $120000-135000 \mathrm{Tk}$. \\
\hline
\end{tabular}

From table 3 it is seen that the maintenance cost of CNG operated Auto Rickshaw is more than Battery operated Easy Bike because of high price of $\mathrm{CNG}$ auto rickshaw part. Driver daily income, daily expenses and owner daily income is more in CNG operated Auto Rickshaw than Battery operated Easy bike.

\subsubsection{Structure of CNG Auto Rickshaw and Easy Bike}

Table 4: Comparison of Structure of CNG operated Auto Rickshaw and Battery operated Easy Bike.

\begin{tabular}{|l|l|l|}
\hline Factors & CNG operated Auto Rickshaw & Battery operated Easy Bike \\
\hline Frame (Body) & Strong & Weak \\
\hline Braking system & TMC brake system & Rear drum(Brake in 2 wheel) \\
\hline Light & Front and back light & Front light \\
\hline Sitting Arrangement & 5 passengers & 6 passengers \\
\hline $\begin{array}{l}\text { Safety aspect of the } \\
\text { system }\end{array}$ & Better than easy bike & Worse than CNG \\
\hline Speed & $50 \mathrm{~km} /$ hour & $30 \mathrm{~km} / \mathrm{hour}$ \\
\hline Fuel used & Compressed Natural Gas & Electrical energy \\
\hline
\end{tabular}

Table 4 shows the comparison of structure of various component i.e frames, light, braking system, sitting arrangement, fuel of CNG operated Auto Rickshaw and Battery operated Easy Bike.

\subsubsection{Safety Aspect of Vehicle}

CNG operated auto rickshaw: As per the government rule CNG operated auto rickshaw drivers must go through BRTC (Bangladesh Road Transport Corporation) training to acquire driving license. From interviewing drivers it is found that drivers do not go through BRTC training. They acquire license from the owner/company known as number two license.

Capacity of passenger carrying is three, but it is commonly found that CNG Auto Rickshaws carry more than three i.e five passengers (Fig.3). Two passengers are sat on the both side of the driver. This makes the driver 
difficult to drive but for money incoming the driver does not think about the safety of the passengers as well as for himself. This often causes accident and injury to both driver and the passenger.

Battery operated easy bike: As per the capacity of the battery and structure usually a battery operated easy bike should carry three passengers, but locally another sitting arrangement for three more passengers are fixed in the structure. This carrying of six passengers makes the speed of the bike slower. Secondly, it is observed that no indicator light is attached to the back and front side of the body (Fig. 4). This makes the vehicle unsafe for driving on the road without back indicator (left/right). Anytime accident may occur while driving on the highway or turning left or right.

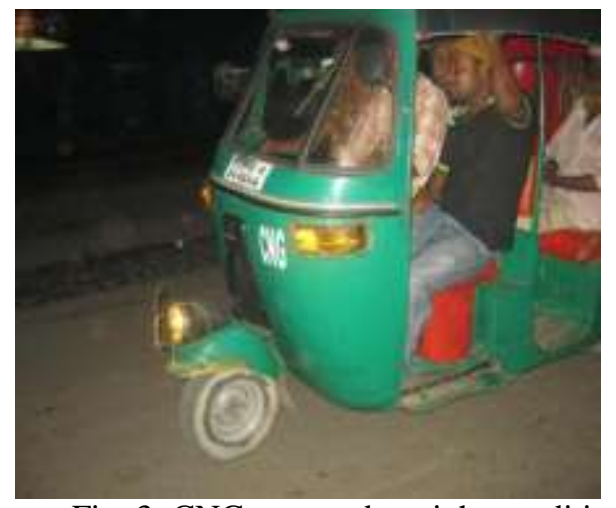

Fig. 3: CNG powered at night condition.

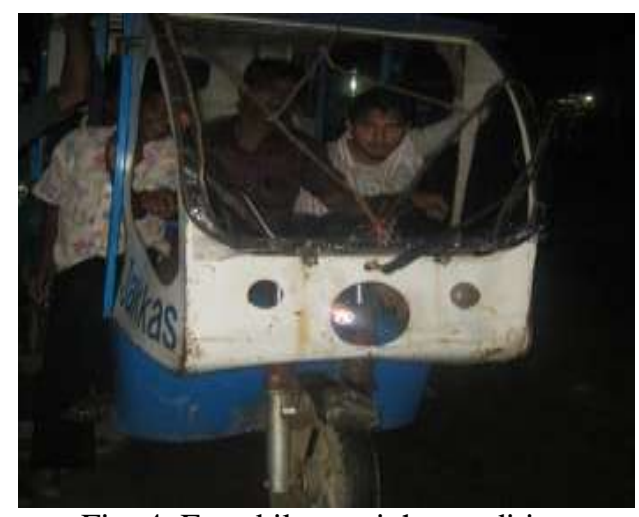

Fig. 4: Easy bike at night condition.

Driving hours: Driving hour for CNG operated Auto Rickshaws is averagely 8 hours/day and for battery Operated easy bikes are 6 hours. It is to be mentioned that every night from 11 pm to 6 am battery is charged for 7-8 hours.

Distance passed by CNG operated Auto Rickshaw and battery operated Easy bike: According to CNG operated auto rickshaws around 80-90 kilometer per day is run by the vehicle. But by the battery operated easy bike it runs 30-40 kilometer per day.

Passenger's comments: Passengers say that CNG Auto Rickshaws is better than Easy bike. Because the safety aspect, speed, comfort ability and so on of CNG auto rickshaw are more reliable than easy bike.

\subsection{Concept Scoring}

Concept scoring is used when increased resolution will better differentiate among competing concepts. In this stage, the team weighs the relative importance of the selection criteria and focuses on more refined comparisons with respect to each criterion. The concept scores are determined by the weighted sum of the ratings [8]. To find out the difference between CNG auto rickshaw and Easy Bike, concept scoring method are used.

Table 5: The concept scoring matrix.

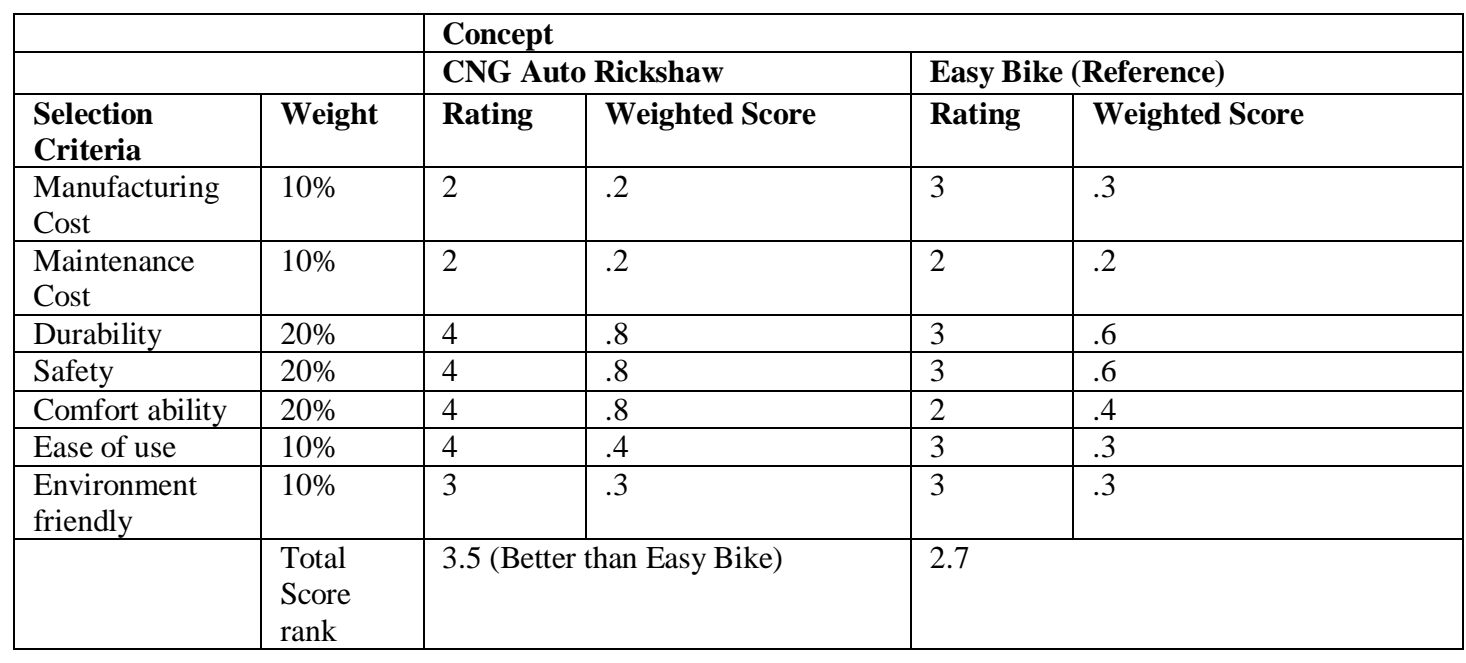


From table 5 it is seen that CNG operated Auto Rickshaw is better than Battery operated Easy Bike. Easy bike has given reference to calculate scoring easily. Weight is determined by manufacturer. This weight is multiplied with rating then scores are determined by the weighted sum of the ratings.

The need for additional resolution to distinguish among competing concepts, a final scale is recommended from 1 to 5 :

\subsection{Findings}

\begin{tabular}{|l|l|}
\hline Relative Performance & Rating \\
\hline Much worse than reference & 1 \\
\hline worse than reference & 2 \\
\hline Same as reference & 3 \\
\hline Better than reference & 4 \\
\hline Much better than reference & 5 \\
\hline
\end{tabular}

From data analysis, findings are as follows:

- CNG operated Auto Rickshaw is more costlier than the Battery operated Easy Bike in Sylhet city.

- The number of CNG operated Auto Rickshaw is more than the Battery operated Easy Bike .

- Braking system, lighting position is stronger in CNG operated Auto Rickshaw than Battery operated Easy Bike.

- Electrical and Mechanical problem is more faced by Battery operated Easy Bike than the CNG operated Auto Rickshaw.

- Driver and Owner daily income is more from CNG Auto Rickshaw than Battery operated Easy Bike.

- Sitting Arrangement is more comfortable in CNG operated Auto Rickshaw than Battery operated Easy Bike.

- Safety aspect of the system for CNG Auto Rickshaw is more reliable than Battery operated Easy Bike.

- Driver of the CNG operated Auto Rickshaw is more efficient than the Battery operated Easy Bike because of their training facilities.

- Distance traveled by the CNG operated Auto Rickshaw is more than the Battery operated Easy Bike.

\section{CONCLUSION}

From the study of Battery operated Easy Bike and CNG operated Auto Rickshaw in terms of cost it is seen that the manufacturing cost and Maintenance cost are little bit higher for CNG operated Auto Rickshaw than that of Battery operated Easy Bike because of complex structure of CNG operated Auto Rickshaw.

It is found that CNG operated Auto Rickshaw is more comfortable than the Battery operated Easy Bike for its better sitting arrangement. The sitting arrangement of Battery operated Easy bike is not acceptable and clumsy and the sitting capacity of the passenger is more than the actual. This makes the transport to move slow.

From the mechanical point of view, CNG operated Auto Rickshaw consists better Braking system, controlling power and steering than the Battery operated Easy Bike. For the safety purpose CNG powered Auto rickshaw is safer than then Battery powered Easy bike, because of better lighting system.

CNG powered Auto rickshaw driver are more efficient than the Battery powered Easy bike because of their training facilities.

From the driver and the passenger point of view both of them like the CNG powered Auto rickshaw. From their comments it is assumed that the CNG powered Auto rickshaw are better transport system in our country.

For the environment issue, Battery operated Easy Bike is more environment friendly than the CNG operated Auto Rickshaw when at running condition. But the battery of Battery operated Easy Bike is not environment friendly, because the battery is dumped in open space. As battery contains harmful chemical known as lead-acid battery. This makes the land polluted and as well as the air. Further such research is required in other cities of Bangladesh where those two transports are used popularly.

\section{REFERENCES}

[1] Anil K. Rajvanshi ,A Paper under the title "Electric and improved cycle rickshaw as a sustainable transport system for India". Nimbkar Agricultural Research Institute (NARI) Published in CURRENT SCIENCE, Vol. 83, NO. 6, 25 September 2002.

[2] A Research Title of IPRO 351 is "Solar/Battery Hybrid Three Wheeled Auto Rickshaw for India" in December 2006.

[3] Auto Rickshaw (Wikipedia, the free encyclopedia)<http://en.wikipedia.org/wiki/Auto_rickshaw.

[4] Jarret, under Dr. Nigel Clark, A thesis paper titled "Heavy duty vehicle emission is testing" Mechanical and Aerospace department, in West Virginia University was published in December 2000. 
[5] Gair, S., A. Cruden, J. McDonald, and B. Hredzak, An articles titled "Electronic differential with sliding mode controller for a direct wheel drive electric vehicle" at International Conference on Mechatronics (Journal of Asian Electric Vehicles) was published in 2004.

[6] Mohammed Abu Mallouh, Bradley Denman, Brian Surgenor, Brant Peppley, A journal paper under the title “A Study of Fuel Cell Hybrid Auto Rickshaws Using Realistic Urban Drive Cycles" was published in Jordan Journal of Mechanical and Industrial Engineering (JJMIE) in January 2010.

[7] T. Hofman, S.G. van der Tas, W. Ooms, E.W.P. van Meijl, and B.M. Laugeman ,A research paper based on "Development of a Micro-Hybrid System for a Three Wheeled Motor Taxi" at Stavanger, Norway, was published in 2009.

[8] Karl T. Ulrich and Steven D. Eppinger, Product Design and Development- , Chapter- 7, Page 134- Concept Scoring. 